\title{
Rho Guanine Nucleotide Exchange Factor 4 (Arhgef4) Deficiency Enhances Spatial and Object Recognition Memory
}

\author{
Ki-Seo Yoo ${ }^{1}$, Kina Lee ${ }^{1}$, Yong-Seok Lee ${ }^{2}$, Won-Jong $\mathrm{Oh}^{3}$ and Hyong Kyu Kim ${ }^{1 *}$ \\ ${ }^{1}$ Department of Medicine and Microbiology, Graduate Program in Neuroscience, College of Medicine, Chungbuk National \\ University, Cheongju 28644, ${ }^{2}$ Department of Physiology, Department of Biomedical Science, Seoul National University \\ College of Medicine, Seoul 03080, ${ }^{3}$ Neurovascular Unit Research Group, Korea Brain Research Institute, Daegu 41062, Korea
}

\begin{abstract}
Guanine nucleotide exchange factors (GEFs) play multiple functional roles in neurons. In a previous study, we reported that Arhgef4 (Rho guanine nucleotide exchange factor 4) functioned as a negative regulator of the excitatory synaptic function by sequestering postsynaptic density protein 95 (PSD-95). However, the role of Arhgef4 in behavior has not been examined. We performed comprehensive behavioral tests in knockout (KO) mice to investigate of the effects of Arhgef4 deficiency. We found that the expressed PSD-95 particle size was significantly increased in hippocampal neuronal cultures from Arhgef $4 \mathrm{KO}$ mice, which is consistent with the previous in vitro findings. Arhgef $4 \mathrm{KO}$ mice exhibited general motor activity and anxiety-like behavior comparable to those of the wild type littermates. However, spatial memory and object recognition memory were significantly enhanced in the Arhgef $4 \mathrm{KO}$ mice. Taken together, these data confirm the role of Arhgef4 as a negative synaptic regulator at the behavioral level.
\end{abstract}

Key words: Arhgef4, PSD-95, Spatial memory, Recognition

\section{INTRODUCTION}

Rho guanine nucleotide exchange factors (GEFs) are involved in the activation of Rho family GTPases by accelerating the exchange of GDP to GTP. Moreover, due to their multiple domains, GEFs act as functional and structural regulators within the postsynaptic regions of neurons in response to external stimuli $[1,2]$. Thus, GEFs play a crucial role in various behaviors, such as anxiety, learning, and memory in experimental animals and also in human pathological conditions [2]. For example, the genetic deletion of Kalirin7, a GEF of excitatory synapses for Racl and RhoG, shows normal object recognition but impaired passive avoidance fear memory in Kalirin7 knockout (KO) mice [3]. The lack of collybis-

Submitted October 9, 2020, Revised October 12, 2020,

Accepted October 12, 2020

* To whom correspondence should be addressed. TEL: 82-43-261-2867, FAX: 82-43-272-1603 e-mail:hkkim69@chungbuk.ac.kr tin, a GEF of inhibitory synapses selectively activating the small GTPase Cdc42, results in a reduced capability of spatial learning and enhances anxiety-like behavior in collybistin-deficient mice [4].

Arhgef4, also known as Asef1, Adenomatous polyposis coli (APC)-stimulated GEF 1, was identified as a functional linker protein connecting the tumor suppressor APC and G-protein signaling, suggesting its role in colon cancer [5]. Although Arhgef4 is highly expressed in the brain [6,7], information on its function in the brain is limited. In our previous study, we suggested that Arhgef4 functions as a negative regulator in excitatory synapses, reducing the level of postsynaptic density protein 95 (PSD-95, also known as synapse-associated protein 90), a major postsynaptic scaffolding protein [8]. PSD-95-deficiency causes memory impairment $[9,10]$. The downregulation of Arhgef4 increases PSD-95, but not Homer1, another postsynaptic density scaffolding protein. Conversely, the overexpression of Arhgef4 decreases PSD-95. Correspondingly, downregulation of Arhgef4 by RNA interference increases the frequency and amplitude of the miniature excitatory 
synaptic current (mEPSC) and its overexpression decreases them [11]. However, these cellular and molecular studies were not confirmed at the systemic or behavioral levels in experimental animals. Consequently, in this study, we examined the behavior of Arhgef4 KO mice. Results showed that the ablation of Arhgef4 improved spatial and recognition memories, again suggesting that Arhgef4 functions as a synaptic negative regulator in the postsynaptic regions of excitatory synapses.

\section{MATERIALS AND METHODS}

\section{Transgenic animals}

Arhgef4 KO mice (Arhgef4 ${ }^{\text {tmla(KOMP)Wtsi }}$, MGI Cat\# 5782024, RRID:MGI:5782024) were purchased from the National Institutes of Health (NIH)-sponsored Knockout Mouse Program (KOMP repository, University of California at Davis, CA, USA) [12]. Het-

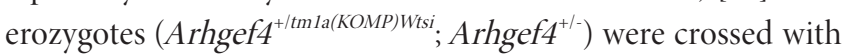
heterozygotes to produce wild-type (WT, Arhgef $4^{+/+}$), heterozygous mutants (Hetero, Arhgef $4^{+-}$), and homozygous mutants (Homo, Arhgef $4^{-1}$ ). Genotyping was performed using the indicated primer sets according to the KOMP information. Further information on mouse generation and targeting strategies are available at the Mouse Genome Informatics ${ }^{1}$ (MGI, http://www.informatics.jax. org) [13].

\section{RT-PCR and western blotting}

Arhgef4 deficiency in Arhgef4 KO mice was examined by RTPCR and western blotting. For RT-PCR, $5 \mu \mathrm{g}$ of the total RNAs purified from the brains of WT, Hetero, and Homo were subjected to reverse transcription using the oligo dT primer for 3'UTR of Arhgef4 mRNA, or a gene specific primer (Arhgef4-RT: 5'-gggcctgatggtataggcc-3) and SuperScript III (Cat\# 18080-051, Invitrogen, Carlsbad, CA) and subsequently amplified by PCR (primers for Arhgef4 mRNA 3'-untranslated regions, Arhgef4-S: 5'-tccetggttccaggttagtg-3', Arhgef4-A: 5'-gcagccaggtcactttcat-3'; $\beta$-actin mRNA, $\beta$-actin-S: 5'-gcgcaagtactctgtgtgga-3', $\beta$-actin-A: 5'-agcgccaaaacaaaacaaaa-3'; Arhgef4 mRNA coding regions: Arhgef41500-S: 5'-ggaagccagaacagaagcag-3', Arhggef4-coding-A: 5'-ggttgtctgatggatg-3'). Arhgef4 expression was examined on western blots containing $40 \mu \mathrm{g}$ each of brain lysates from WT mice, Homo mice, and rats (Sprague Dawley, Samtaco Bio Korea, Osan, Korea), and $10 \mu \mathrm{g}$ of human embryonic kidney (HEK) cells. Synaptic protein expression was detected on western blots containing $3 \mu \mathrm{g}$ (for synaptophysin and $\alpha$-tubulin) or $25 \mu \mathrm{g}$ (for PSD-95, Homer-1,

\footnotetext{
${ }^{1}$ http://www.informatics.jax.org/mgihome/nomen/IKMC_schematics. $\operatorname{shtml}(\mathrm{J}: 148605, \mathrm{~J}: 173534)$
}

GluA1, and GluN1) of brain lysate from each genotyped mouse. All protein were separated on $8 \%$ acrylamide gels and transferred to a PVDF membranes (Millipore, Burlington, MA, USA). The antibodies used in western blotting included rabbit polyclonal anti-Arhgef4 antibodies (raised by Arhgef $4 \mathrm{~N}$-terminal regions of 105 amino acids including APC-binding regions and $\mathrm{SH}$ domain, Accession\# EDL14459; AbClone, Seoul, Korea), polyclonal antiPSD-95 antibodies (Cell Signaling Technology, Danvers, MA, USA), monoclonal anti-Homer 1 antibody (Synaptic Systems, Göttingen, Germany), polyclonal anti-GluAl antibody (Millipore), monoclonal anti-GluN1 antibody (Millipore), polyclonal anti-synaptophysin antibody (Millipore), and monoclonal anti- $\alpha$-tubulin antibodies (Clone B-5-1-2, Sigma-Aldrich, St. Louis, MO, USA). The protein levels of lysates were quantified by bicinchoninic acid assay (Pierce ${ }^{\mathrm{TM}}$ BCA assay, Thermo Fisher Scientific, Rockford, IL, USA). All RT-PCR and western blot analyses were performed more than twice to confirm reproducibility of data.

\section{Quantitative real-time PCR}

The $0.5 \mu \mathrm{g}$ of total RNAs from the brain of WT, Hetero, or Homo was synthetized to cDNAs, and subsequently used to PCR containing SYBR Green ready mix (TOPreal ${ }^{\text {TM }}$ One-step RT qPCR Kit, Enzynomics, Daejeon, Korea) and primers (identical sets used for RT-PCR analysis) by real-time PCR system (CFX96 Touch Real-Time PCR Detection System, Bio-Rad, Laboratory, Hercules, CA, USA). The relative change of Arhgef4 expression in Homo or Hetero mouse to that in WT mouse was analyzed by $2^{-\Delta \Delta \mathrm{Ct}}$ method $[14,15]$. Total RNAs from two animals per genotype were subjected to qRT-PCR analysis and the reactions were repeated.

\section{Neuronal culture, immunostaining, and image analysis}

Hippocampi were isolated from the brain of postnatal day one (P1) animals and used for culture as previously described [16]. After twelve days, the cultures were infected with Sindbis virus encoding green fluorescent protein (GFP) [11] for $12 \mathrm{~h}$, followed by immunostaining with monoclonal anti-PSD-95 antibody (Clone 6G6-1C9, Thermo Fisher Scientific) and Cy3-conjugated goat anti-mouse IgG (Jackson ImmunoResearch Labs, West Grove, PA, USA). Fluorescent images were acquired with confocal microscopy (Zeiss LSM 800 Airyscan, Carl Zeiss Microscopy GmbH, Jena, Germany), and the acquired images were analyzed with the ImageJ program (ver 1.46r, NIH, Bethesda, MA, USA). Image acquisition and analysis were performed in blinded experiments and image analysis was performed as previously described [16]. The data are presented as mean \pm standard error of the mean (SEM). The Student's unpaired $t$-test was applied to reveal statistical differences between the two groups. Statistical analyses were performed using 
GraphPad Prism (ver 5.0, GraphPad Software, La Jolla, CA, USA).

\section{Behavioral tests}

All experiments using mice were performed in accordance with the approved animal protocols and the guidelines of the Institutional Animal Care and Use Committee of the Chungbuk National University (CBNUA-1236-19-01). Fewer than four mice were placed in cages on a reversed light-dark cycle and were permitted food and water ad libitum. All behavioral tests were conducted on the F2-F3 generation of both male and female mice produced by intercrossing of the heterozygous mice $\left(\right.$ Arhgef $\left.4^{+/}\right)$. Mice $>11$ weeks of age (35 animals, WT: 12, Hetero: 11, Homo: 12) were used in open field, elevated plus-maze, object location memory (OLM), and novel object recognition memory (ORM) tests in a sequence. Behavioral tests were performed in the middle phase of the dark cycle. Between trials, the surface of the arena or maze was cleaned with $70 \%$ ethanol and distilled water. Data acquisition and analysis for all tests were performed blinded to genotype.

\section{Open field test}

Open field tests were performed as described [17]. Tests were performed in an opaque white plastic arena $(33 \times 33 \mathrm{~cm}, 33 \mathrm{~cm}$ high). Mice were placed in the periphery of the arena, and their behavior was recorded for 15 min using a camcorder (HDR-CX100, SONY, Tokyo, Japan). For the measurement of general motor activity, path length (total distance) and speed of movement in the total area were analyzed by Ethovision XT (Noldus, Wageningen, the Netherlands). For anxiety-related behavior, entries to the central area and times spent in the central area (infield, square $20 \times 20 \mathrm{~cm}$ ) were analyzed.

\section{Elevated plus-maze test}

Mice were placed in the center of an elevated plus-maze $(4 \times 30$ $\mathrm{cm}$ arms, $60 \mathrm{~cm}$ above floor level, $18 \mathrm{~cm}$ high non-transparent side walls), and their paths were recorded by a camcorder (HDRCX100, SONY, Tokyo, Japan). Time spent in each arm and entries into each arm over 10 min were manually scored and changed to percentage. More details are described in a previous study [18].

\section{Rotarod test}

Rotarod tests to measure motor skills of mice were performed as described [19]. Mice were placed on the rotating rod with a start speed of $4 \mathrm{rpm}$, acceleration rate $20 \mathrm{rpm} / \mathrm{min}$ (47600, Ugo Basile, Gemonio VA, Italy) and tested for $14 \mathrm{~min}$. Three times trials each 14 min with 15 min interval were performed. Duration time on the rod before mouse falls off and rod spin speed (rapid per minute, rpm) when mouse falls off were scored and averaged.

\section{Object location memory test}

The OLM test was performed as previously described [20,21] and included training and test sessions. Before training, mice were habituated for $5 \mathrm{~min}$ per day for 4 days in an arena $(33 \mathrm{~cm} \times 33$ $\mathrm{cm}, 33 \mathrm{~cm}$ high, less than 45 LUX) and then habituated for $15 \mathrm{~min}$ per day over the next 2 days. One side of the experimental box included a spatial cue. In the training session, mice were allowed to freely explore two identical objects placed in the box for $10 \mathrm{~min}$. During the test session $24 \mathrm{~h}$ after the training, mice were placed back in the same box, but one of the objects was moved to a new location. Interaction with each object (defined as sniffing and/or head within $1 \mathrm{~cm}$ of the object) was manually scored for analysis. Mice that showed more than $10 \%$ preference for each object in the training session were excluded from the subsequent memory tests. The discrimination index was calculated as follows: (time exploring the novel object - time exploring the old)/(time exploring novel+old) $\times 100$.

\section{Novel object recognition memory test}

After the OLM tests, mice were placed in the arena for the novel ORM tests with the same objects situated in the same location, and allowed to explore for $10 \mathrm{~min}$. Twenty-four hours later, the mice were placed back into the experimental box containing an old object and a new object in the same locations and allowed to explore for $5 \mathrm{~min}$. Mice that showed more than a 10\% preference for each object in the training session were excluded from the subsequent memory tests.

\section{Statistical analyses}

Data normality was assessed with the Kolmogorov-Smirnov test, the D'Agostino \& Pearson Omnibus normality test, or the Shapiro-Wilk normality test. One-way analysis of variance (ANOVA) was used to compare more than two groups. Post hoc comparisons were conducted using Dunnett's or Bonferroni's multiple comparison tests. If the data did not follow a Gaussian distribution, a nonparametric Kruskal-Wallis test was used to compare more than two groups. The Student's unpaired $t$-test was used to reveal statistical differences between the two groups. We did not conduct any tests for outliers. The data are presented as mean \pm SEM. Statistical analyses were performed using GraphPad Prism.

\section{RESULTS}

\section{Arhgef4-deficient mice exhibited increase of PSD-95 par- ticle size in neurons}

To investigate the role of Arhgef4 in behaviors, we generated Arhgef4 KO mice by crossing heterozygous mutant mice (Arh- 

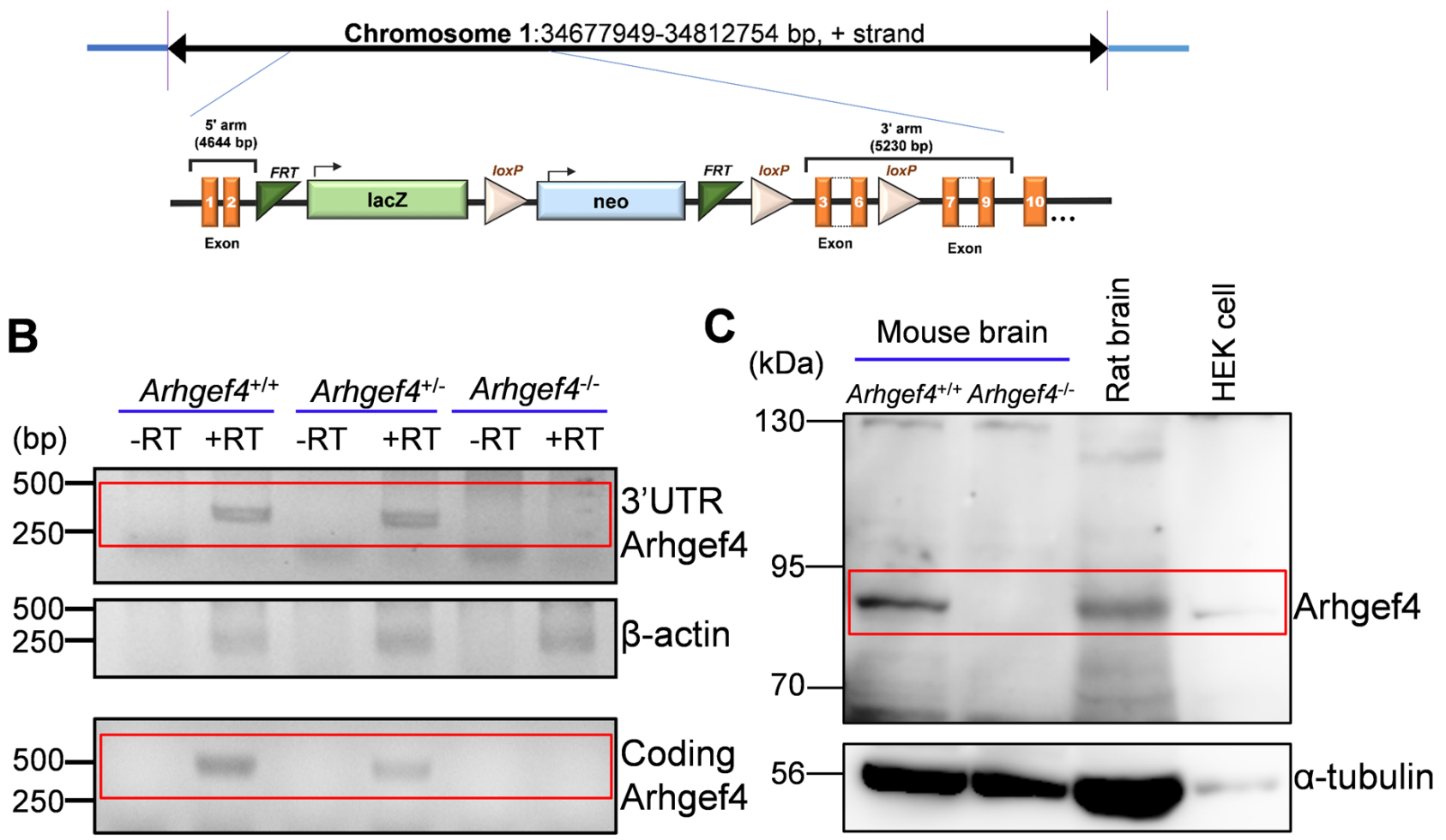

Fig. 1. Arhgef4 knockout by gene disruption. (A) Chromosomal region of Arhgef4 gene and diagram of vector for knockout (modified information provided by KOMP). FRT: flippase recognition target, lacZ: $\beta$-galactosidase, neo: neomycin, loxP: locus of X-over P1. (B) RT-PCR analysis. Five micrograms of total RNA was transferred to cDNAs of Arhgef4 and $\beta$-actin by reverse transcription. The 3'untranslated regions of their cDNAs near the poly (A) tail or coding regions were amplified by PCR. (C) Forty micrograms of brain lysates from WT mice $\left(\right.$ Arhgef $\left.4^{+/+}\right)$, Homo mice $\left(\right.$Arhgef $\left.4^{-/}\right)$, or rats, and $10 \mu \mathrm{g}$ of human embryonic kidney (HEK) cells were separated by $8 \%$ acrylamide gel. The western blotting assay was performed using rabbit polyclonal anti-Arhgef4 antibodies (specific for N-terminal regions of mouse Arhgef4; see Materials and Methods). After the detection of Arhgef4, the blots were stripped and subsequently reprobed with anti- $\alpha$-tubulin antibody.

Table 1. Fold change of Arhgef4 expression in KO brain

\begin{tabular}{|c|c|c|}
\hline Genotype & $\begin{array}{c}\text { Average } \Delta \Delta C t \\
(\text { Mean } \pm S D, N=4)\end{array}$ & $\begin{array}{l}\text { Expression fold change } \\
\text { to wild type }\left(2^{-\Delta \Delta \mathrm{Ct}}\right)\end{array}$ \\
\hline Arhgef4 $^{+/-}$ & $0.85 \pm 0.20$ & $0.555(0.483 \sim 0.637)$ \\
\hline Arhgef4 $4^{-1}$ & $4.29 \pm 0.46$ & $0.051(0.037 \sim 0.070)$ \\
\hline
\end{tabular}

$\mathrm{SD}$, standard deviation.

gef4 $^{+/ t m l a(K O M P) W t s i}$, Fig. 1A) [12]. Arhgef4 deficiency in the brain was examined by performing RT-PCR and western blotting analysis. As shown in Fig. 1B, the Arhgef4 transcript was not detected in Homo mice brains. We consistently did not detect Arhgef4 protein in Homo mice brain lysates; whereas Arhgef4 was detected in the rat brain and HEK cell lysates (Fig. 1C). The quantity of Arhgef4 transcript in Homo mice was reduced to approximately $0.5 \%$ of that in WT mice (Table 1 ).

\footnotetext{
${ }^{2}$ https://www.mousephenotype.org/data/genes/MGI:2442507
}

Arhgef4 KO homo mice exhibited decreased body weights (data not shown), which is consistent with the data of the International Mouse Phenotyping Consortium ${ }^{2}$ (IMPC, www.mousephenotype. org) [22]. PSD-95, a major scaffolding protein in the post-synaptic regions of excitatory synapses, regulates receptors such as NMDA and AMPA and plays a crucial role in experience-dependent plasticity $[23,24]$. Our previous study demonstrated that downregulation of Arhgef4 by RNA interference increases PSD-95 levels in the dendrites, and conversely, overexpression of Arhgef4 decreases PSD-95 levels [11]. Accordingly, we examined PSD-95 level in hippocampal neurons of Homo mice. The ablation of Arhgef4 significantly increased the size of PSD-95 particles (Fig. 2C), but not the number of those in the dendrites (data not presented). On the other hand dendritic protrusions significantly decreased in hippocampal neurons of the homozygous mice (Fig. 2D). Arhgef4 ablation did not change the expression levels of PSD-95 and synaptic proteins, including Homer-1, GluA1, GluN1, or synaptophysin, 
A
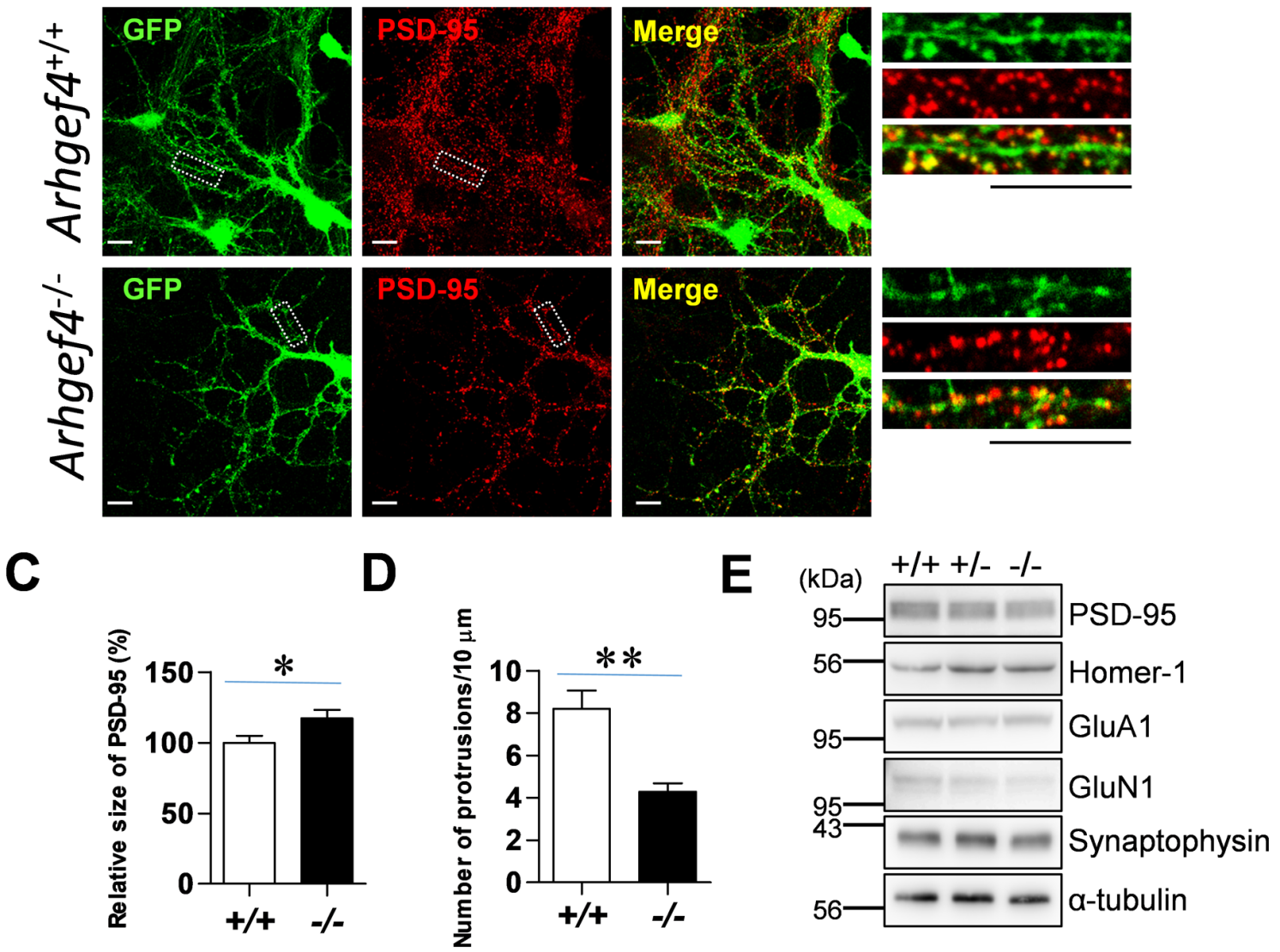

Fig. 2. Lacking Arhgef4 decreased the number of dendritic protrusions but increased the size of PSD-95 particles. (A) Hippocampal neurons isolated from WT and Homo mice were cultured. Neurons were infected with GFP Sindbis viruses and immunostained with monoclonal PSD-95 antibodies. Scale bar: $10 \mu \mathrm{m}$. (B) The selected dendrites were straightened and enlarged. Scale bar: $10 \mu \mathrm{m}$. (C) The size of PSD-95 particles was increased in the neurons of Arhgef4 knockout mice (Arhgef4 $4^{+/+}: 100.0 \% \pm 4.93 \%, \mathrm{~N}=15$ dendrites; Arhgef4 $4^{-1}: 117.3 \% \pm 5.98 \%, \mathrm{~N}=14$ dendrites, two-tailed unpaired $t$-tests: $\left.{ }^{*} \mathrm{p}<0.05\right)$. (D) The number of dendritic protrusions per $10 \mu \mathrm{m}$ was decreased in the neurons of Arhgef4 knockout mice $\left(\right.$ Arhgef $4^{+/}: 8.2 \pm 0.86, \mathrm{~N}=15$ dendrites; Arhgef4 ${ }^{-1}: 4.3 \pm 0.39, \mathrm{~N}=14$ dendrites, two-tailed unpaired $t$-tests: $\left.{ }^{* *} \mathrm{p}<0.01\right)$. (E) Ablation of Arhgef4 gene did not change synaptic protein expression levels, including PSD-95, in the brain. Brain lysates ( $25 \mu \mathrm{g}$ of lysate for PSD-95, Homer-1, GluA1, and GluN1, $3 \mu \mathrm{g}$ of lysate for synaptophysin, a-tubulin) from WT, Hetero, and Homo mice were loaded and subjected to western blotting analysis.

depending on the copy number of the Arhgeft gene (Fig. 2E).

\section{General motor activity and anxiety-like behavior in Arh- geft KO mice were not altered}

First, we examined the general locomotive activity of Arhgef4 $\mathrm{KO}$ mice by performing open field tests. The KO mice did not show any significant changes in motor activity, as assessed by distance moved and speed, when compared with WT or Hetero mice (Fig. 3A, B). In addition, the time spent in the center of the open field did not differ among genotypes, suggesting that the anxiety level was not affected by Arhgef4 deletion (Fig. 3C, D). We further examined anxiety-like behavior by performing elevated plus-maze tests and found no significant difference among genotypes (Fig. $3 \mathrm{E}, \mathrm{F})$. Finally, we tested motor skills by performing rotarod tests.
Latencies to fall from the rotarod were comparable among genotypes, suggesting that Arhgef4 deficiency does not affect motor function in the rotarod tests (Fig. 3G, H).

\section{Long-term spatial and recognition memories in Arhgeft KO mice were enhanced}

Given that PSD-95 is a key player in synaptic plasticity, which may underlie learning and memory, we examined the long-term memory of Arhgef4 KO mice in the OLM and novel ORM tests. OLM is dependent on hippocampal function [20, 25-27], whereas ORM engages several brain regions, including the hippocampus and surrounding cortical regions [20]. Notably, we found that both OLM and ORM test results were significantly enhanced in Homo mice compared to WT mice (Fig. 4), suggesting that both spatial 


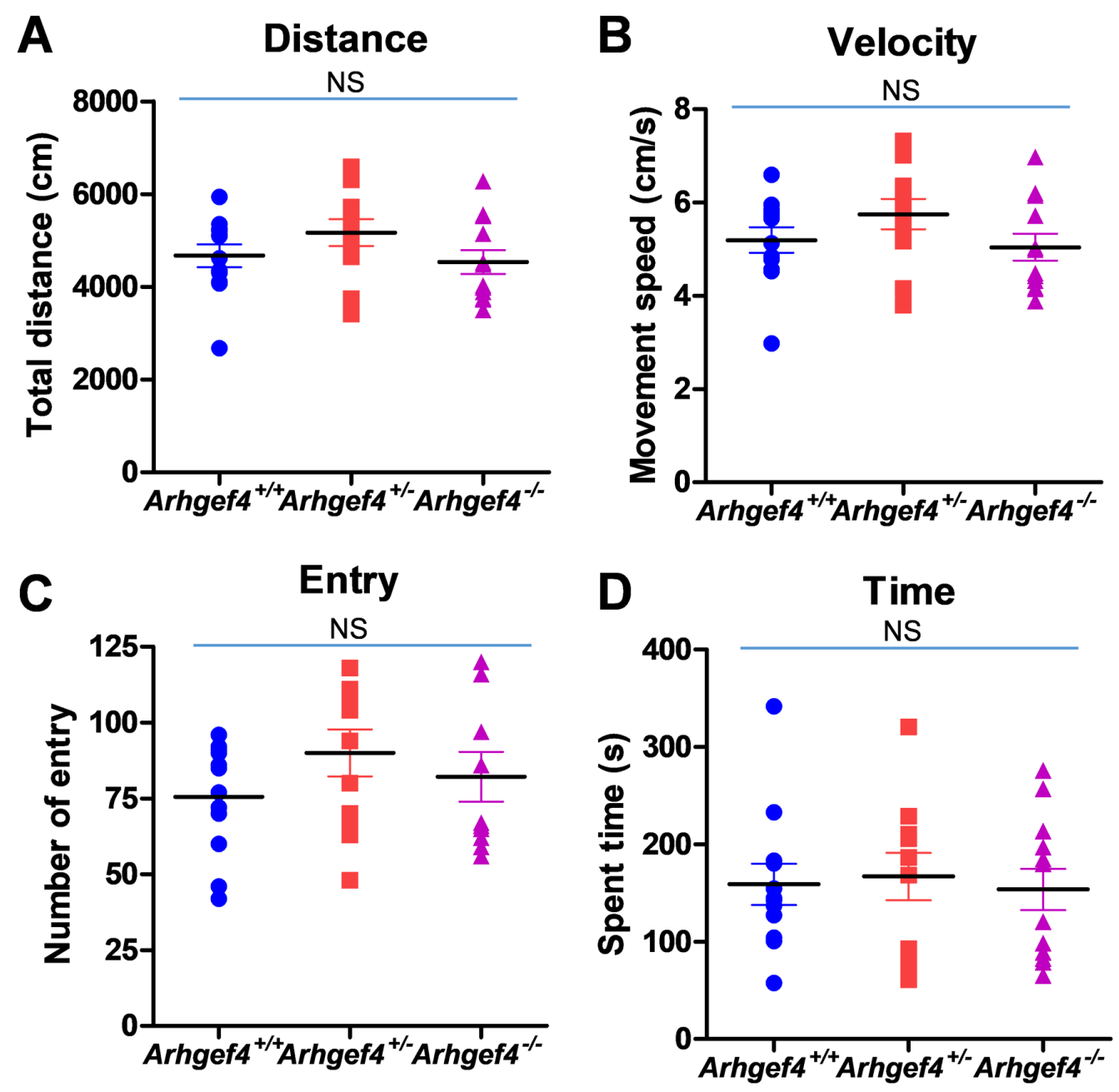

Fig. 3. General motor activity or anxiety-like behavior was not different among genotypes. (A, B) Arhgef4 knockout did not change the path distance

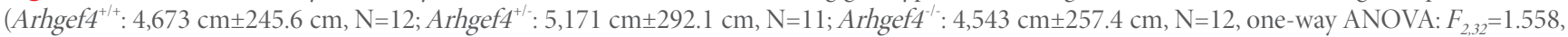
$\mathrm{p}=0.2261$, NS: not significant) and speed of movement $\left(\right.$ Arhgef $^{+/+}: 5.19 \mathrm{~cm} / \mathrm{sec} \pm 0.27 \mathrm{~cm} / \mathrm{sec}, \mathrm{N}=12 ;$ Arhgef ${ }^{+/}: 5.75 \mathrm{~cm} / \mathrm{sec} \pm 0.32 \mathrm{~cm} / \mathrm{sec}, \mathrm{N}=11 ;$ Arhgef $^{-1}: 5.04 \mathrm{~cm} / \mathrm{sec} \pm 0.29 \mathrm{~cm} / \mathrm{sec}, \mathrm{N}=12$, one-way ANOVA: $F_{2,32}=1.556, \mathrm{p}=0.2264$, NS: not significant) in the total area. (C, D) Arhgef4 knockout did not change the entry number to the central area $\left(\right.$ Arhgef4 $^{+/+}: 75.58 \pm 5.24, \mathrm{~N}=12 ;$ Arhgef $^{+/}: 90.00 \pm 7.76, \mathrm{~N}=11 ;$ Arhgef4 $^{-/}: 82.17 \pm 8.17, \mathrm{~N}=12$, one-way ANOVA: $F_{2,32}=1.003, \mathrm{p}=0.3781$, NS: not significant) and the time spent in the central area $\left(\right.$ Arhgef $^{+/+}: 158.9 \mathrm{sec} \pm 21.06 \mathrm{sec}, \mathrm{N}=12 ;$ Arhgef4 $^{+/-}: 167.0$ $\sec \pm 24.38 \mathrm{sec}, \mathrm{N}=11$; Arhgef4 $4^{-1}: 153.7 \mathrm{sec} \pm 21.24 \mathrm{sec}, \mathrm{N}=12$, one-way ANOVA: $F_{2,32}=0.0902, \mathrm{p}=0.9140$, NS: not significant). (E) Arhgef4 knockout did not change the percent of entry into open arms $\left(\right.$ Arhgef4 $^{+/+}: 44.80 \% \pm 5.11 \%, \mathrm{~N}=12 ;$ Arhgef4 $^{+/}: 41.81 \% \pm 2.26 \%, \mathrm{~N}=11 ;$ Arhgef4 $^{-/}: 37.11 \% \pm 3.57 \%, \mathrm{~N}=12$, one-way ANOVA: $F_{2,32}=1.010, \mathrm{p}=0.3754$, NS: not significant). (F) Arhgef4 knockout did not change the percent of time spent in open arms (Arhgef4 ${ }^{+/+}$: $36.69 \% \pm 4.36 \%, \mathrm{~N}=12 ;$ Arhgef4 $^{+/}: 33.01 \% \pm 3.69 \%, \mathrm{~N}=11 ;$ Arhgef4 $^{-1}: 27.88 \% \pm 3.25 \%, \mathrm{~N}=12$, one-way ANOVA: $F_{2,32}=0.8914$, p=0.420, NS: not significant). (G) Arhgef4 knockout did not change the duration time on the rod before mice fall off $\left(\right.$ Arhgef ${ }^{+/+}: 245.4 \mathrm{sec} \pm 70.42 \mathrm{sec}, \mathrm{N}=12 ;$ Arhgef4 ${ }^{+/}: 172.5$ $\sec \pm 33.46 \mathrm{sec}, \mathrm{N}=11$; Arhgef4 $^{-1}: 344.4 \mathrm{sec} \pm 62.28 \mathrm{sec}, \mathrm{N}=12$, one-way ANOVA: $F_{2,32}=2.132, \mathrm{p}=0.1352$, NS: not significant). (H) Arhgef4 knockout did not change the mean rpm when mice fall off $\left(\right.$ Arhgef $^{+/}: 32.97 \mathrm{rpm} \pm 2.22 \mathrm{rpm}, \mathrm{N}=12 ;$ Arhgef $^{+/}: 34.33 \mathrm{rpm} \pm 1.42 \mathrm{rpm}, \mathrm{N}=11 ;$ Arhgef4 $^{-/}: 37.31 \mathrm{rpm} \pm 1.14$ rpm, $\mathrm{N}=12$, Kruskal-Wallis test: $\mathrm{p}=0.1546$, NS: not significant).

memories and recognition memories are affected by Arhgef 4 deletion.

\section{DISCUSSION}

In this study, we demonstrated that deficiency of Arhgef4, a postsynaptic GEF, does not alter general motor activity and anxiety- like behavior (Fig. 3), but significantly improved long-term spatial and recognition memories (Fig. 4). Our previous report suggested that Arhgef4 could function as a negative synaptic regulator in cultured neurons [11]. The present study confirms the negative regulation of synaptic PSD-95 by Arhgef4.

Consistent with previous reports [6,7], Arhgef4 was enriched in the brain in our study. In addition, Arhgef 4 showed marginal 

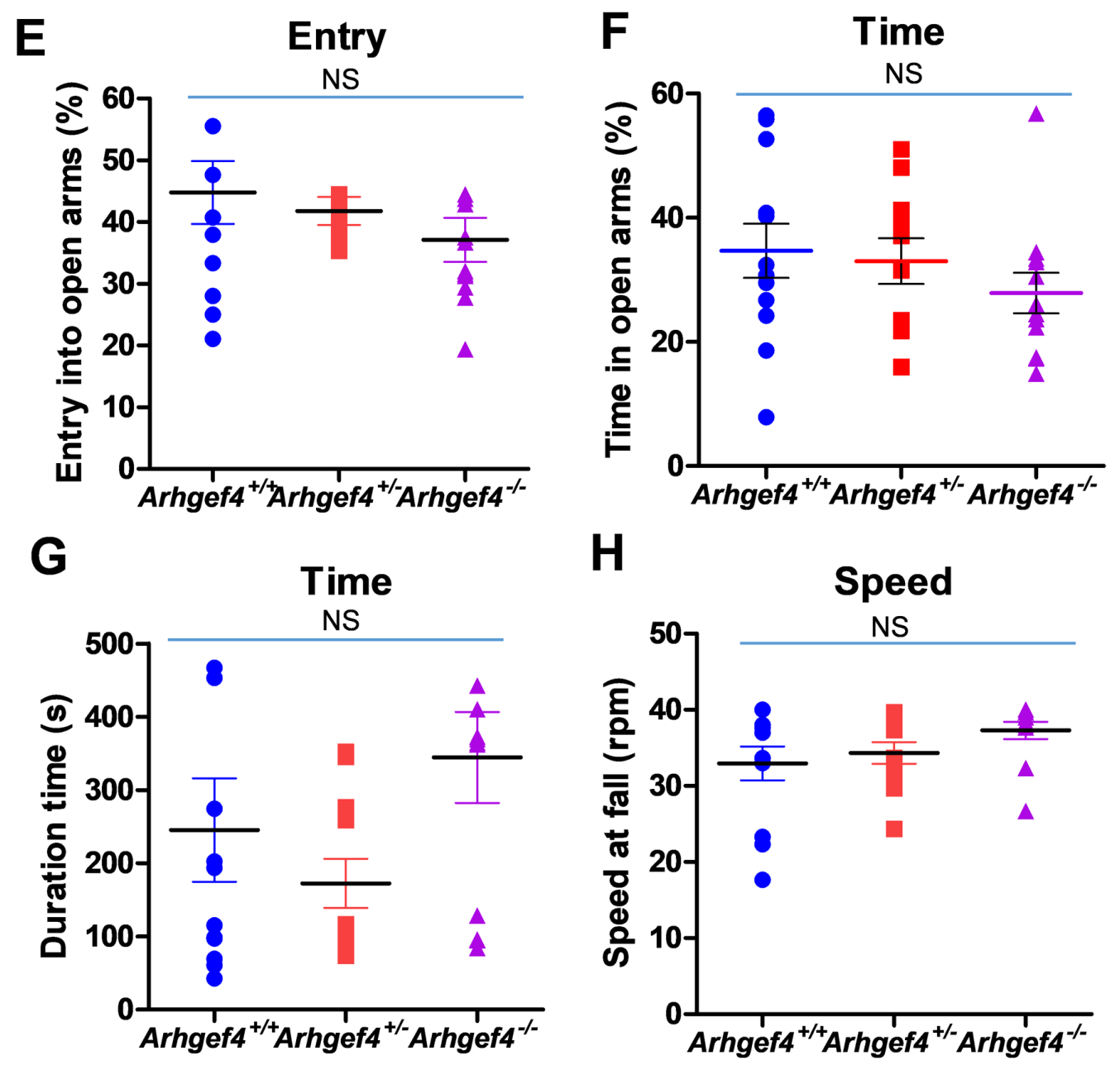

Fig. 3. Continued.

expression in the lung, intestine, and skeletal muscle, but was not detected in the heart and liver by our RT-PCR analysis (data not shown). Our data are also in line with those of the Human Protein Atlas $^{3}$ (http://www.proteinatlas.org) [28], which show that Arhgef4 is highly expressed in the brain and skin. In particular, expression levels of the cerebral cortex and hippocampal formation are higher than in other brain regions. Daily spatial memory such as OLM is dependent on the hippocampus [20,25-27]. Novel ORM is dependent on some cortex regions such as insular cortex or prefrontal cortex, but only partially on the hippocampus [20]. As indicated by our data, the Arhgef4 expression pattern is consistent with the specific brain regions associated with memory.

PSD-95, a major scaffolding protein in excitatory synapses interacts with many synaptic proteins including signaling molecules,

\footnotetext{
${ }^{3}$ https://www.proteinatlas.org/ENSG00000136002-ARHGEF4/tissue

${ }^{4}$ https://www.mousephenotype.org/data/genes/MGI:2442507
}

receptors, and channels, and has a pivotal role in synaptic assembly and function [8,29]. Moreover, PSD-95 levels at postsynapses in excitatory neurons contribute to a variety of memories in experimental animals $[9,10,30,31]$. Thus, PSD-95 has been the focus of studies on development and synaptic plasticity. In our data, Arhgef4 deficiency did not change PSD-95 expression levels (Fig. 2E). This result is consistent with our previous report that Arhgef4 overexpression can reduce dendritic PSD-95 by sequestering Staufen-containing transporting complexes [11].

Even though there are no effects on viability and mortality, the global Arhgef4 KOs exhibit hematological defects and smaller body weights (IMPC ${ }^{4}$, https://www.mousephenotype.org) [22]. Therefore, we cannot completely exclude any systemic effects on the brain. In order to further consolidate the present results, indepth analyses of specific brain regions in conditional Arhgef $4 \mathrm{KO}$ mice are required.

In conclusion, Arhgef 4 deficiency enhances long-term memory 
A

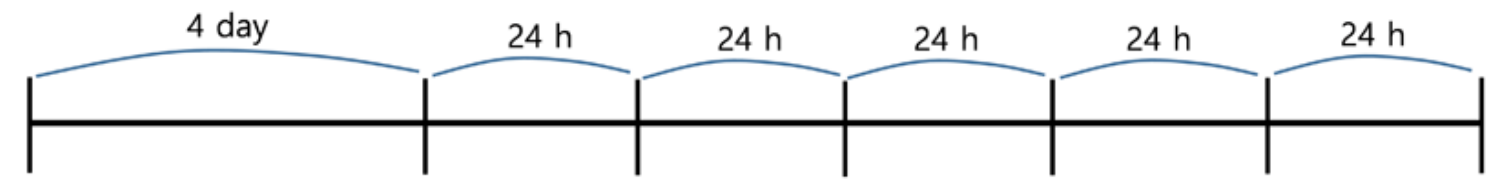

Taming

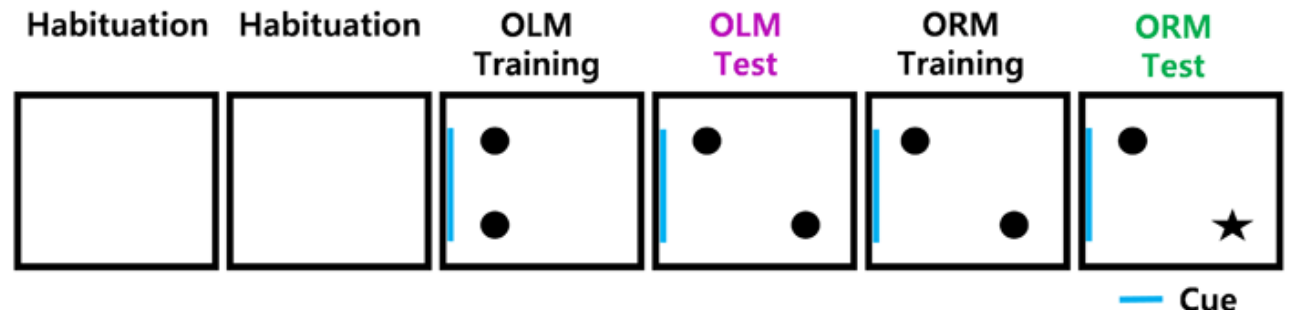

B
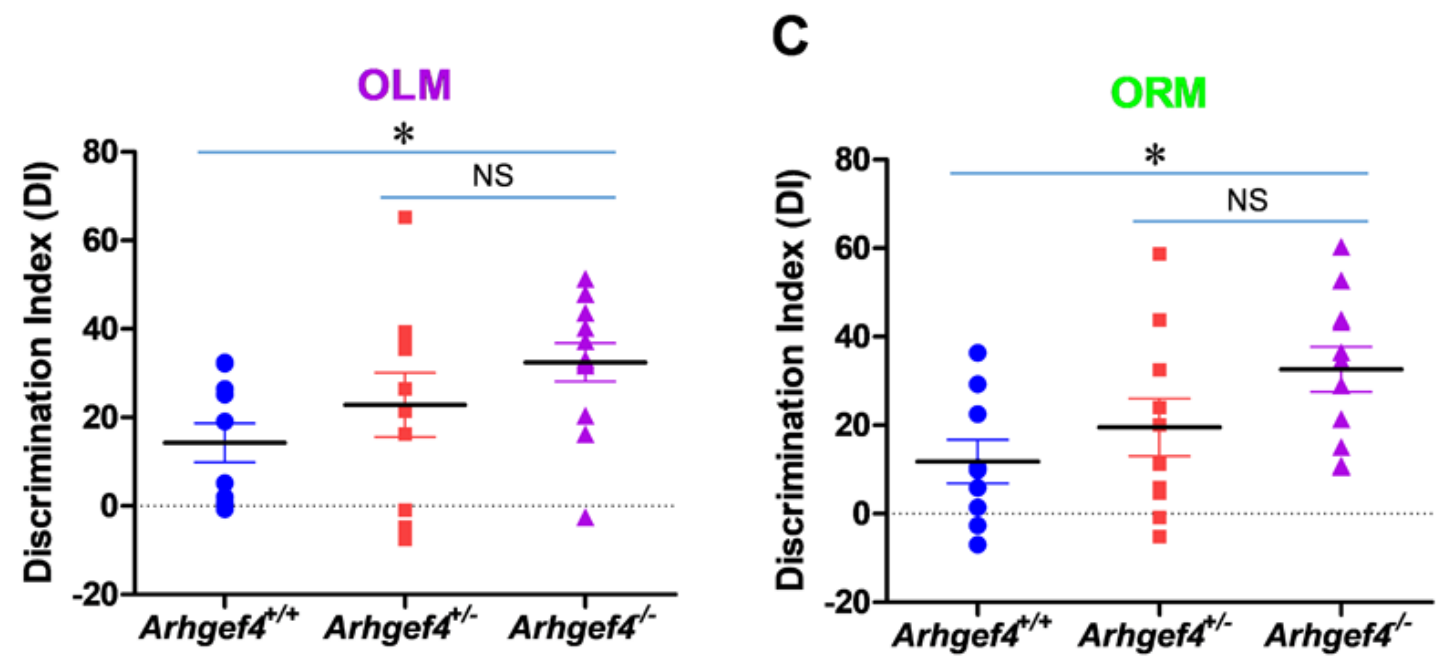

Fig. 4. Object location memory (OLM) and novel object recognition memory (ORM) were increased in Arhgef4 knockout mice. (A) Experimental time lines for the OLM and ORM tests. (B) OLM increased in Arhgef4 knockout mice (Arhgef $4^{++}: 14.29 \pm 4.45, \mathrm{~N}=10 ;$ Arhgef $^{+/}: 22.90 \pm 7.26, \mathrm{~N}=10 ;$ Arhgef4 $^{-/}$: $35.65 \pm 3.2, \mathrm{~N}=11$, one-way ANOVA: $F_{2,28}=4.454, \mathrm{p}=0.0209$; Dunnett's multiple comparison tests: ${ }^{*} \mathrm{p}<0.05$, NS: not significant). (C) ORM increased in $A r$ hgef4 knockout mice $\left(\right.$ Arhgef4 $^{+/+}: 11.80 \pm 4.91, \mathrm{~N}=9 ;$ Arhgef4 $^{+/}: 19.52 \pm 6.51, \mathrm{~N}=10 ;$ Arhgef4 $^{-1}: 32.63 \pm 5.08, \mathrm{~N}=11$, one-way ANOVA: $F_{2,27}=3.608, \mathrm{p}=0.0409$; Dunnett's multiple comparison tests: ${ }^{*} \mathrm{p}<0.05$, NS: not significant).

through increasing synaptic PSD-95 levels, indicating its role as a negative regulator of synaptic plasticity.

\section{ACKNOWLEDGEMENTS}

This research was supported by grants from the Basic Science Research Program through the National Research Foundation of Korea (NRF) funded by the Ministry of Education (NRF2018R1D1A1B07043779) to Hyong Kyu Kim and from the Korea Brain Research Institute (KBRI 20-BR-01-06) to Won-Jong Oh.

\section{REFERENCES}

1. Kiraly DD, Eipper-Mains JE, Mains RE, Eipper BA (2010)
Synaptic plasticity, a symphony in GEF. ACS Chem Neurosci 1:348-365.

2. Miller MB, Yan Y, Eipper BA, Mains RE (2013) Neuronal Rho GEFs in synaptic physiology and behavior. Neuroscientist 19:255-273.

3. Ma XM, Kiraly DD, Gaier ED, Wang Y, Kim EJ, Levine ES, Eipper BA, Mains RE (2008) Kalirin-7 is required for synaptic structure and function. J Neurosci 28:12368-12382.

4. Papadopoulos T, Korte M, Eulenburg V, Kubota H, Retiounskaia M, Harvey RJ, Harvey K, O'Sullivan GA, Laube B, Hülsmann S, Geiger JR, Betz H (2007) Impaired GABAergic transmission and altered hippocampal synaptic plasticity in collybistin-deficient mice. EMBO J 26:3888-3899.

5. Kawasaki Y, Senda T, Ishidate T, Koyama R, Morishita T, 
Iwayama Y, Higuchi O, Akiyama T (2000) Asef, a link between the tumor suppressor APC and G-protein signaling. Science 289:1194-1197.

6. Hamann MJ, Lubking CM, Luchini DN, Billadeau DD (2007) Asef2 functions as a Cdc42 exchange factor and is stimulated by the release of an autoinhibitory module from a concealed C-terminal activation element. Mol Cell Biol 27:1380-1393.

7. Thiesen S, Kübart S, Ropers HH, Nothwang HG (2000) Isolation of two novel human RhoGEFs, ARHGEF3 and ARHGEF4, in 3p13-21 and 2q22. Biochem Biophys Res Commun 273:364-369.

8. Sheng M, Kim E (2011) The postsynaptic organization of synapses. Cold Spring Harb Perspect Biol 3:a005678.

9. Fitzgerald PJ, Pinard CR, Camp MC, Feyder M, Sah A, Bergstrom HC, Graybeal C, Liu Y, Schlüter OM, Grant SG, Singewald N, Xu W, Holmes A (2015) Durable fear memories require PSD-95. Mol Psychiatry 20:913.

10. Nithianantharajah J, Komiyama NH, McKechanie A, Johnstone M, Blackwood DH, St Clair D, Emes RD, van de Lagemaat LN, Saksida LM, Bussey TJ, Grant SG (2013) Synaptic scaffold evolution generated components of vertebrate cognitive complexity. Nat Neurosci 16:16-24.

11. Oh JY, Lim CS, Yoo KS, Park H, Park YS, Kim EG, Lee YS, Kaang BK, Kim HK (2018) Adenomatous polyposis colistimulated GEF 1 (Asef1) is a negative regulator of excitatory synaptic function. J Neurochem 147:595-608.

12. Skarnes WC, Rosen B, West AP, Koutsourakis M, Bushell W, Iyer V, Mujica AO, Thomas M, Harrow J, Cox T, Jackson D, Severin J, Biggs P, Fu J, Nefedov M, de Jong PJ, Stewart AF, Bradley A (2011) A conditional knockout resource for the genome-wide study of mouse gene function. Nature 474:337342 .

13. Mouse Genome Informatics (2020) Diagrams of general structure of IKMC primary alleles and derivative alleles [Internet]. The Jackson Laboratory, Bar Harbor. Available from: http://www.informatics.jax.org/mgihome/nomen/IKMC_ schematics.shtml.

14. Livak KJ, Schmittgen TD (2001) Analysis of relative gene expression data using real-time quantitative PCR and the 2(-Delta Delta C(T)) Method. Methods 25:402-408.

15. Pfaffl MW (2001) A new mathematical model for relative quantification in real-time RT-PCR. Nucleic Acids Res 29:e45.

16. Yoo KS, Lee K, Oh JY, Lee H, Park H, Park YS, Kim HK (2019) Postsynaptic density protein 95 (PSD-95) is transported by KIF5 to dendritic regions. Mol Brain 12:97.

17. Bailey KR, Crawley JN (2009) Anxiety-related behaviors in mice. In: Methods of behavioral analysis in neuroscience (Buccafusco JJ, ed). 2nd ed. CRC Press, Boca Raton, FL.

18. Komada M, Takao K, Miyakawa T (2008) Elevated plus maze for mice. J Vis $\operatorname{Exp}(22): 1088$.

19. Deacon RM (2013) Measuring motor coordination in mice. J Vis $\operatorname{Exp}(75): \mathrm{e} 2609$.

20. Vogel-Ciernia A, Wood MA (2014) Examining object location and object recognition memory in mice. Curr Protoc Neurosci 69:8.31.1-8.31.17.

21. Lee YS, Ehninger D, Zhou M, Oh JY, Kang M, Kwak C, Ryu HH, Butz D, Araki T, Cai Y, Balaji J, Sano Y, Nam CI, Kim HK, Kaang BK, Burger C, Neel BG, Silva AJ (2014) Mechanism and treatment for learning and memory deficits in mouse models of Noonan syndrome. Nat Neurosci 17:1736-1743.

22. International Mouse Phenotyping Consortium (2020) Gene: Arhgef4 [Internet]. International Mouse Phenotyping Consortium. Available from: https://www.mousephenotype.org/ data/genes/MGI:2442507.

23. Xu W (2011) PSD-95-like membrane associated guanylate kinases (PSD-MAGUKs) and synaptic plasticity. Curr Opin Neurobiol 21:306-312.

24. El-Husseini AE, Schnell E, Chetkovich DM, Nicoll RA, Bredt DS (2000) PSD-95 involvement in maturation of excitatory synapses. Science 290:1364-1368.

25. Vogel-Ciernia A, Matheos DP, Barrett RM, Kramár EA, Azzawi S, Chen Y, Magnan CN, Zeller M, Sylvain A, Haettig J, Jia Y, Tran A, Dang R, Post RJ, Chabrier M, Babayan AH, Wu JI, Crabtree GR, Baldi P, Baram TZ, Lynch G, Wood MA (2013) The neuron-specific chromatin regulatory subunit BAF53b is necessary for synaptic plasticity and memory. Nat Neurosci 16:552-561.

26. Barrett RM, Malvaez M, Kramar E, Matheos DP, Arrizon A, Cabrera SM, Lynch G, Greene RW, Wood MA (2011) Hippocampal focal knockout of CBP affects specific histone modifications, long-term potentiation, and long-term memory. Neuropsychopharmacology 36:1545-1556.

27. Haettig J, Stefanko DP, Multani ML, Figueroa DX, McQuown SC, Wood MA (2011) HDAC inhibition modulates hippocampus-dependent long-term memory for object location in a CBP-dependent manner. Learn Mem 18:71-79.

28. The Human Protein Atlas (2020) ARHGEF4 [Internet]. The Human Protein Atlas. Available from: https://www.proteinatlas.org/ENSG00000136002-ARHGEF4/tissue.

29. Won S, Levy JM, Nicoll RA, Roche KW (2017) MAGUKs: multifaceted synaptic organizers. Curr Opin Neurobiol 43:94-101.

30. Migaud M, Charlesworth P, Dempster M, Webster LC, 
Watabe AM, Makhinson M, He Y, Ramsay MF, Morris RG, Morrison JH, O'Dell TJ, Grant SG (1998) Enhanced longterm potentiation and impaired learning in mice with mutant postsynaptic density-95 protein. Nature 396:433-439.
31. Elkobi A, Ehrlich I, Belelovsky K, Barki-Harrington L, Rosenblum K (2008) ERK-dependent PSD-95 induction in the gustatory cortex is necessary for taste learning, but not retrieval. Nat Neurosci 11:1149-1151. 